\title{
Effects of Long-Term UV Exposure on the Performance of Cement Plasters Integrated with Thermochromic Paint and PCMs for Building Facade Applications
}

\author{
Shahrzad Soudian ${ }^{1}$, Umberto Berardi ${ }^{1}$ and Nadia O. Laschuk ${ }^{2}$ \\ ${ }^{1}$ Ryerson University, 350 Victoria St. Toronto, ON, Canada. shahrzad.soudian@ryerson.ca ; \\ uberardi@ryerson.ca \\ ${ }^{2}$ Ontario Tech University, 2000 Simcoe Street North, Oshawa, ON, Canada. nadia.laschuk@uoit.net
}

\begin{abstract}
The exterior finish layer in building facades is exposed to considerable environmental loads, which can reduce the service life of the materials, increasing the need for replacement. New climate challenges impose to look more carefully at the long-term performance and durability of building components and materials. Thermal stresses due to daily temperature fluctuations and UV exposure can significantly damage facades and degrade their performance. This research measures the long-term performance of a responsive cementitious finish plaster. The developed cement plaster is combined with phase change materials (PCMS), and thermochromic (TC) pigments to control solar radiation and surface temperatures dynamically on the exterior façade year around. The main objective of the study is to quantify the effect of long-term UV exposure on the optical performance of the cement plasters. $P C M s$ with three different melting temperatures of $18^{\circ} \mathrm{C}, 24^{\circ} \mathrm{C}$, and $28^{\circ} \mathrm{C}$ were combined with two different colors of blue and red TC paint with a transition temperature of $31^{\circ} \mathrm{C}$. Accelerated UV aging of the samples was performed using lab tests to simulate exposure to UV radiation for two years. The solar reflectance of the samples was characterized before and after the accelerated UV aging tests. The results of the aging tests revealed that UV exposure impacts the solar reflectance of the finish material based on the method of integrating the TC paint to the cement plaster. In the case of TC paint applied to the surface, the solar reflectance of the plasters with only the TC is reduced by 15\% after aging, while the ones combined with PCMs have a similar solar reflectance value after aging.
\end{abstract}

Keywords: Durability, Building Façade, Thermal Energy Storage, Thermal Stress, Accelerated Aging, Urban Heat Island.

\section{Introduction}

One of the main climate challenges in urban areas is the shifting weather patterns with increasing trends of temperature fluctuations in dense cities that can impact urban thermal comfort. The urban heat island (UHI) effect particularly is a known phenomenon that refers to the occurrence of higher ambient temperatures in cities compared to suburban areas (Santamouris et al., 2016). This event is specifically due to higher solar absorption in urban surfaces such as building facades. In addition, the high surface temperatures of facades can lead to higher heat transfer through the building envelope leading to thermal comfort problems and higher energy demands. However, thermal stresses exposed to exterior building façade surfaces can critically impact the durability of the finish materials. The exterior finish layer in buildings is exposed to considerable environmental loads, namely thermal stresses and UV radiation, that over long-term exposure leads to degradation (Pisello, 2017). The temperature fluctuations experienced on the exterior surface of finish materials decrease the durability of the material (Hernandez-Perez et al., 2014; Pisello, 2017). 
Increasing the lifetime of the building façade by reducing exterior thermal stresses, therefore, becomes critical. By reviewing the literature, several strategies can be found that have been proposed for regulating external solar and thermal loads. The most prominent strategy is the application of cool/white or reflective coatings on exterior roof and façade surfaces. Such coatings have high solar reflectance and emittance, thus leading to lower surface temperature and better performance under UV exposure (Ascione et al., 2018). With the growing application of cool coatings globally, the literature has mainly focused on their benefits in the cooling season. However, the heating penalty associated with lower solar gains on the surfaces with cool coatings could be comparable to their advantages in the cooling season (Ascione et al., 2018; Garshasbi and Santamouris, 2019).

Several strategies to optimize the performance of reflective coatings have been evaluated, such as combining reflective coatings with phase change materials (PCMs) (Pisello et al., 2017). This combination has been proposed to benefit from the large heat storage capacity of PCMs to buffer the peak temperatures and decrease the thermal fluctuations, which directly affect the durability of the finish materials (Pisello et al., 2017). Another approach that is gaining attention is the use of dynamic coatings with variable optical properties using thermochromic (TC) coatings or paints (Karlessi et al., 2011; Perez et al., 2018). TC paint changes its colors in response to temperature, allowing a change in its optical properties at a specific transition temperature. The solar reflectance and emittance of the TC paint are increased with higher temperatures as it turns to whiter shades, and as the temperatures go down, the solar absorptivity of the paint is increased. Evaluating the key material properties of these smart materials temperature loads in topic to identify the (Zinzi, 2016). Addition performance of such smart materials, accelera used extensively (Jelle, 2011; Karlessi et al., 2015).

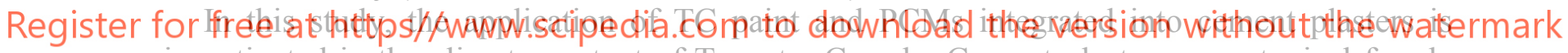
investigated in the climate context of Toronto, Canada. Cement plasters are a typical façade finish material used in different types of buildings in Toronto. The combination of the TC paint and PCMs in this study is used to address both thermal and solar exposure using different mechanisms of dynamic solar control and thermal energy storage. Different configurations of cement plasters with TC paint and PCMs have been developed and characterized for their optical and thermal properties. The aim of this paper is to evaluate how long-term exposure to solar radiation, particularly the negative impact of UV degradation impacts the optical performance of the samples. The objective is to compare the main optical property of the samples, namely solar reflectance in the primary stage to the post-aged stage using lab tests.

\section{Methodology}

\subsection{Development of Cement Plaster Samples}

The cement plaster was made based on the ASTM C926-18b standard for exterior plaster applications and mixed with microencapsulated PCMs and TC pigments. Three PCMs with different melting temperatures $\left(\mathrm{T}_{\mathrm{mp}}\right)$ of $18^{\circ} \mathrm{C}, 24^{\circ} \mathrm{C}$, and $28^{\circ} \mathrm{C}$ were used. Blue and red Leuco 
dye TC pigments with a transition temperature of $31^{\circ} \mathrm{C}$ were used in this study. Based on the dynamic properties of the TC paints selected, the color transition to white occurs above $31^{\circ} \mathrm{C}$, and below $31^{\circ} \mathrm{C}$, the paint turns back to its original color. The cement plaster samples were made into $10 \mathrm{~cm} \times 10 \mathrm{~cm}$ tiles with a thickness of $1.2 \mathrm{~cm}$. The PCMs and the TC paints were each added to the tiles based on a mass fraction of $2.5 \%$ of the base cement plaster tiles. Therefore, samples with both PCMs and the TC paint included a total of 5\% of the materials and a $95 \%$ ratio of the cement plaster mixture. More detailed information on the sample production process can be found in Soudian and Berardi (2019).

One of the main variables in this study is two different types of cement plasters considering the integration of the TC paint in the plaster. Type 1 samples include the mixing of both the PCMs and the TC pigments inside the cement plaster mixture, as shown in Figure 1a. Type 2 samples include the mixing of PCMs inside the cement plaster mixture, while the TC paint is painted on the surface of the plaster tiles (Figure 1b). A total of twelve Type 1 samples and eight Type 2 samples were created.

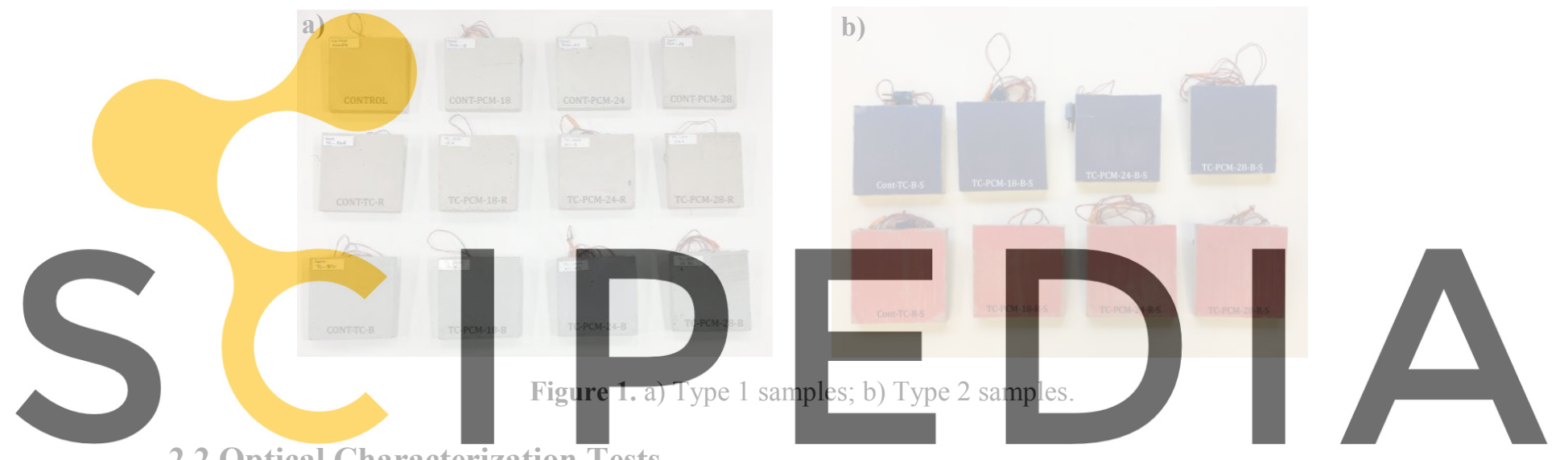

\subsection{Optical Characterization Tests}

Register fDy fine samples were subjected to one heating cycle and one cooling cycle prior to the measurements. The heating cycle was performed in an oven set to $45^{\circ} \mathrm{C}$, which is above the transition temperature of the PCMs and the TC paints. In the cooling cycle, the samples were cooled to $8^{\circ} \mathrm{C}$ in a fridge. Figure 2 shows the color change of the Type 2 samples in both cycles. The spectral reflectance of the samples was measured according to the ASTM E903-12. The measurements were made using a Perkin Elmer's Lambda $750 \mathrm{~S}$ UV-Vis/NIR spectrophotometer with $60 \mathrm{~mm}$ integrating spheres. The reflectance measurements were conducted in the range of 300-2500 $\mathrm{nm}$ with $10 \mathrm{~nm}$ steps (Soudian et al., 2020).
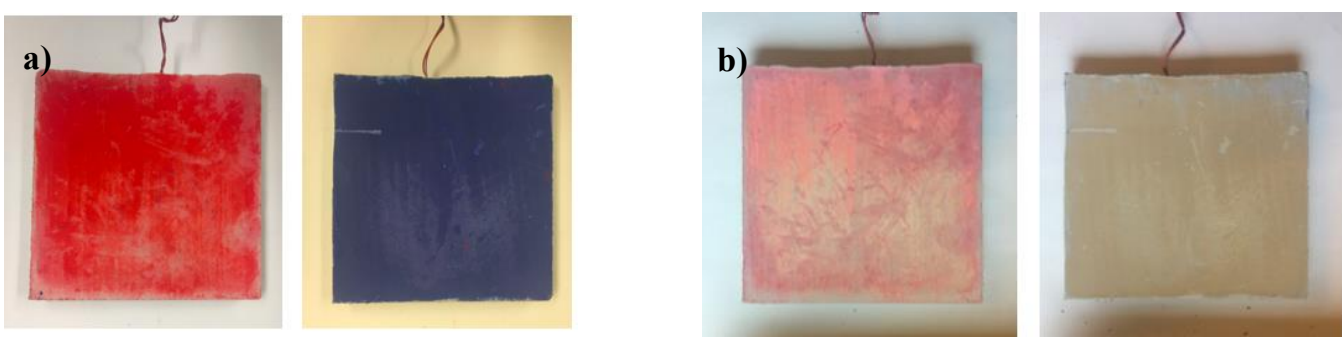

Figure 2. a) Type 2 samples at $8^{\circ} \mathrm{C}$; b) Type 2 samples at $45^{\circ} \mathrm{C}$. 


\subsection{Accelerated UV Aging}

A QUV accelerated weather testing machine was used for the accelerated UV aging tests. The tests were performed according to ASTM G154-16. The UV acceleration factor (AFUV) was calculated from Equation (1), where $\phi_{\text {lab }}$ indicates the total UV energy in the aging machine, and the $\phi_{\text {nat }}$ is the average natural outdoor energy for a given period.

$$
A F_{U V}=\phi_{\text {lab }} / \phi_{\text {nat }}
$$

The total UV intensity considered for the $340 \mathrm{~nm}$ UV lamps in the apparatus was set to 1.55 $\mathrm{W} / \mathrm{m}^{2}$, and the total energy calculated for one day of operation of the machine is $12.5 \mathrm{kWh} / \mathrm{m}^{2}$. This setting represents the Cycle 6 configurations of the ASTM G154-16 standard. The average daily solar irradiance value for the city of Toronto is $126 \mathrm{Wh} / \mathrm{m}^{2}$ obtained from Natural Resources Canada (2016). Therefore, the AFUV calculated is 57. Based on the AFUV and the exposure conditions determined by the standard, the samples were aged for seven days representing a two-year exposure to UV radiation. Figure 3 shows the testing apparatus and the cement plaster samples mounted on the QUV machine. The samples were subjected to an 8hour cycle of $\mathrm{UV}$ exposure at $60^{\circ} \mathrm{C}$, followed by a 4-hour cycle of condensation at $50^{\circ} \mathrm{C}$.
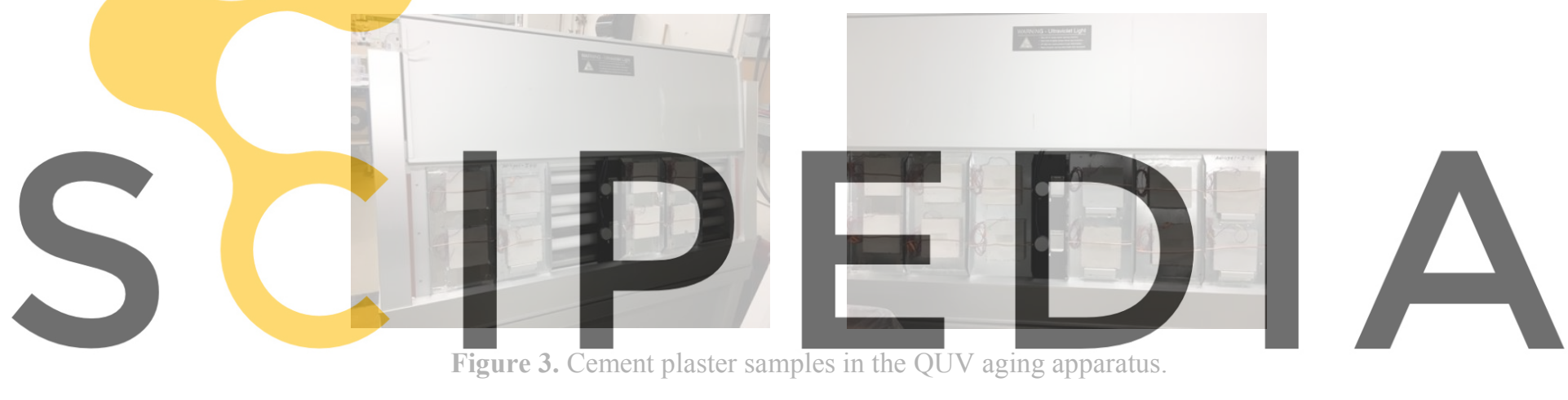

Register f९rfreeglat https//www.scipedia.com to download the version without the watermark

\subsection{Initial Characterization: Pre-Aging}

All the samples showed a greater change in solar reflectance/absorptance in the near-infrared range (NIR) compared to the UV and the visible light (VIS) range, as shown in Figures 4 and 5. A distinct difference between the solar reflectance of Type 1 and Type 2 samples was observed in the heating and cooling cycles. At $45^{\circ} \mathrm{C}$, Type 2 samples with the TC paint on their surface showed an average of $13 \%$ higher range of solar reflectance in the NIR compared to Type 1 samples. The solar reflectance of all the eight Type 2 samples is higher than the control cement plaster sample, having a range of reflectance between $60 \%-80 \%$, while the control sample has an average of $49.5 \%$ solar reflectance. In contrast, considering the importance of solar gain in colder temperatures, at $8^{\circ} \mathrm{C}$, Type 1 samples showed $12 \%$ higher solar absorptance in the NIR compared to the Type 2 samples. A much lower solar absorptance performance was observed in the case of Type 2 samples, as shown in Figure 8 b, and all the samples have a lower percentage of solar absorptance in the NIR compared to the control sample. 

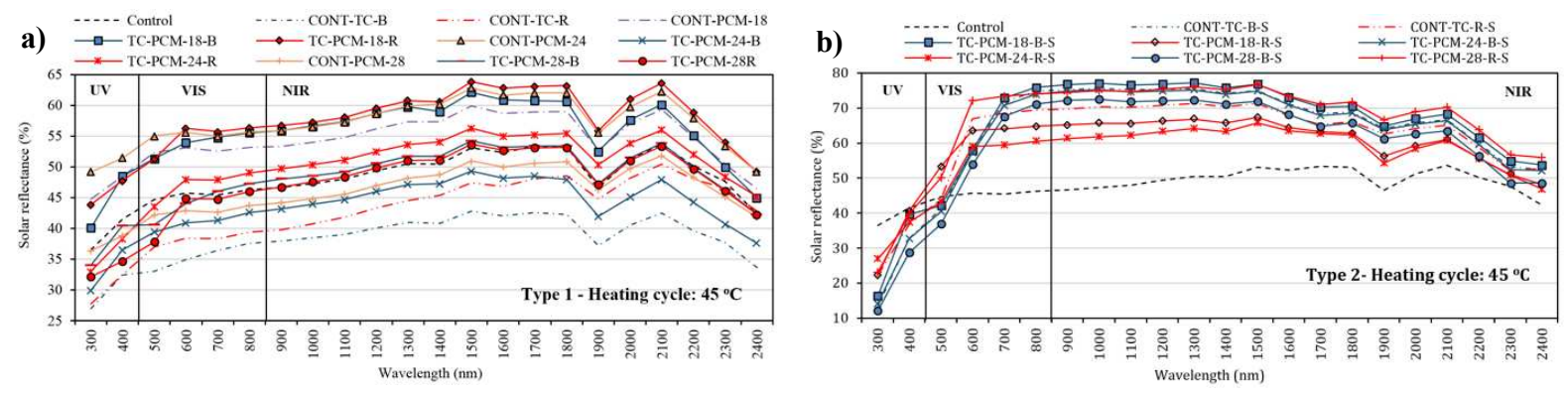

Figure 4. Solar reflectance at $45^{\circ} \mathrm{C}$ : a) Type 1 samples; b) Type 2 samples.

The solar reflectance results of the samples with the blue and the red paint shows a higher solar reflectance recorded for the blue colored Type 2 samples. However, in Type 1 samples, all the mixed and control samples with the red TC paint showed a higher range of solar reflectance in the heating cycle. In Type 1 samples, the average solar reflectance of the control sample is higher than the control samples with only the TC paint. Considering the combination of the PCMs with TC paint, the best results are obtained by using the PCM- 18, as the combined samples show a $22 \%$ better performance than the CONT-PCM- 18 sample, and $28 \%$ higher solar reflectance than the control samples with only the TC paint. In the cooling cycle, the overall solar absorption of Type 2 samples is considerably less than the control PCM samples, as well as the combined Type 1. This observation shows that applying the paint on the surface affects the potential to retain solar gains. It is observed that the total solar absorption range of the TC

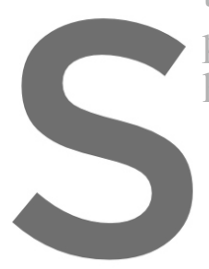
paints on the surface is much lower between 3
heating season for material durability and over
a)
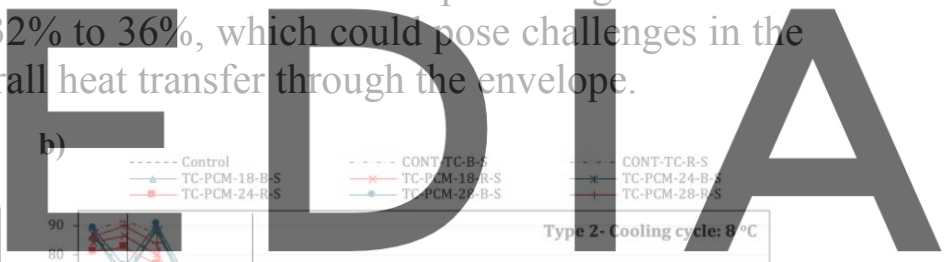

Register for free at https//www.scipedia.com to download the version without the watermark
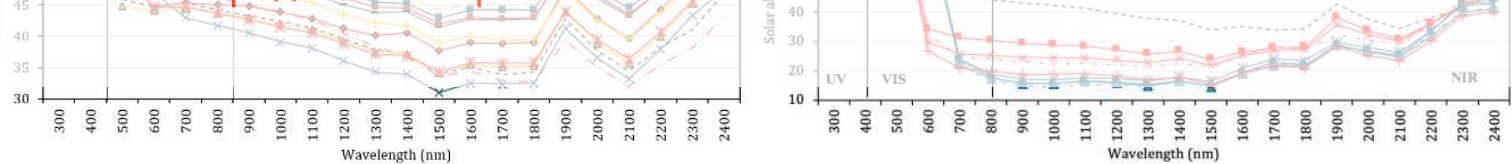

Figure 5. Solar absorptance at $8^{\circ} \mathrm{C}$ : a) Type 1 samples; b) Type 2 samples.

\subsection{Characterization- Post-Aging}

The effect of the two-year accelerated UV aging on the visual appearance of the samples is shown in Figure 6. Compared to the initial images taken prior to the aging (Figure 1), the Type 2 samples have lost their colors, and in Type 1 samples, the slight color differences due to the TC paint is no longer visible. The performance of the samples is expected to be affected due to such considerable color variations. 

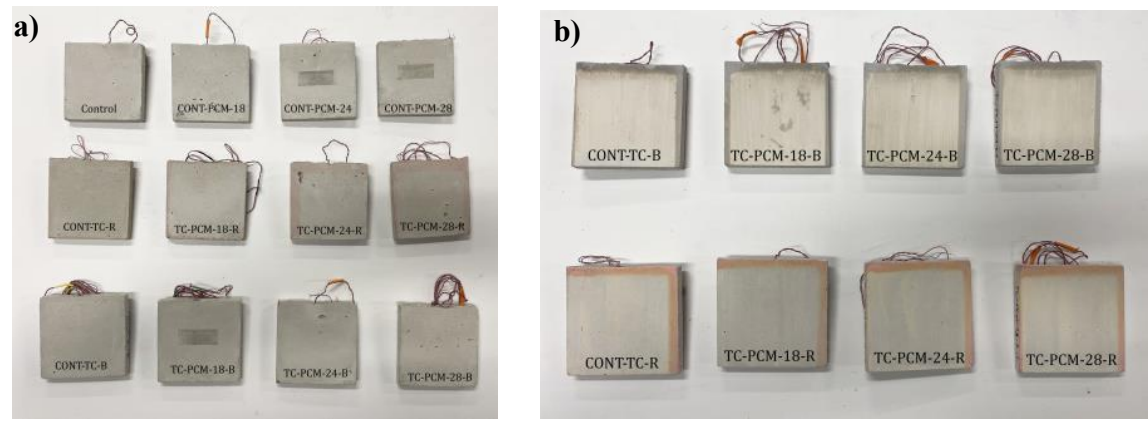

Figure 6. Visual changes to the samples a) Type 1 samples; b) Type 2 samples.

\subsubsection{Solar reflectance measurements: Post-Aging}

The same procedure to measure the solar reflectance of the samples was performed after the two-year aging tests. The results are shown in Figures 7 and 8 for the heating and the cooling cycles. Similar to the pre-aging results, the overall solar reflectance of the samples at $45^{\circ} \mathrm{C}$ is higher in the Type 2 samples compared to Type 1 samples. However, the overall performance of the Type 1 samples in reflecting solar radiation is reduced considerably compared to the control sample. As shown in Figure 7a, the solar reflectance of the control sample in the NIR is higher than all the samples within the 1600-2500 nm wavelength. A general trend could be observed in both types of samples as the post-aging results show an increase in solar reflectance

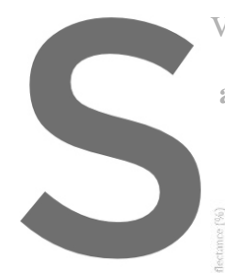
values in the UV and vi
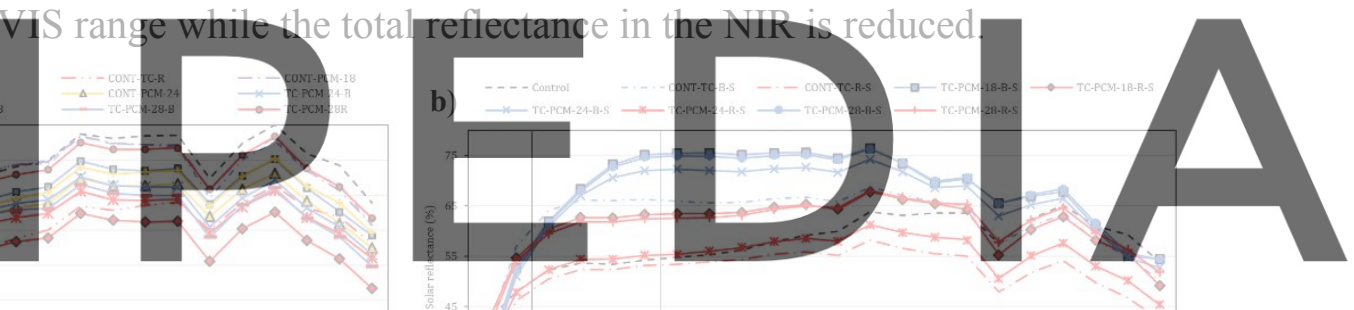

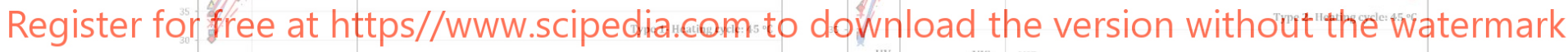

Figure 7. Solar reflectance at $45{ }^{\circ} \mathrm{C}$ - Post-Aging: a) Type 1 samples; b) Type 2 samples.
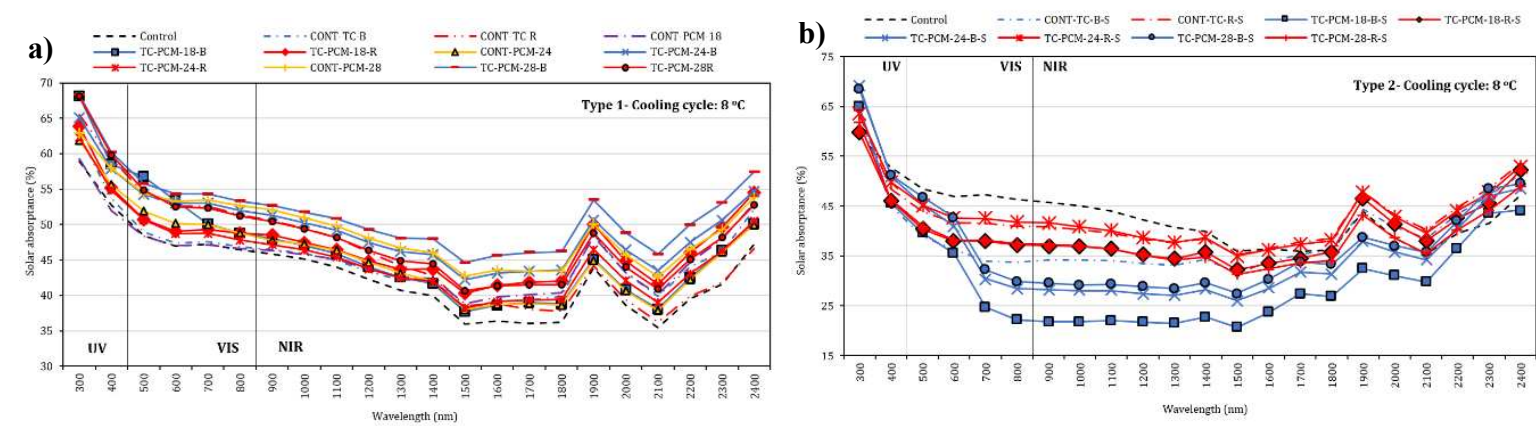

Figure 8. Solar absorptance at $8{ }^{\circ} \mathrm{C}$ - Post-Aging: a) Type 1 samples; b) Type 2 samples.

In the cooling cycle, the aging did not significantly change the solar absorptance characteristic of the Type 1 samples, as shown in Figure 8a, and similar to Figure 5a, the control 
sample holds the lowest rate of solar absorption at $8^{\circ} \mathrm{C}$ in the NIR. The total solar absorptance of the samples with the red paint in Type 2 samples is higher than the blue colored ones. The post-aging results show that the total solar absorptance of Type 2 samples have increased by $10 \%$ in the NIR.

\subsection{Performance Change Comparison}

By reviewing the pre and post aging results of solar reflectance values for all the samples, no specific trend could be established between the color of the TC paint and the $\mathrm{T}_{\mathrm{mp}}$ of the PCMs. To better illustrate the effect of the two-year UV aging on the samples, Figure 9 shows the change in solar reflection characteristic of each sample in the heating cycle. As the figure shows, the impact of aging on the control samples with only the TC paint varies considerably between Type 1 and Type 2 samples. In Type 1 samples, the solar reflectance was increased after aging, in the Type 2 samples, solar reflectance decreased after the surface color faded.

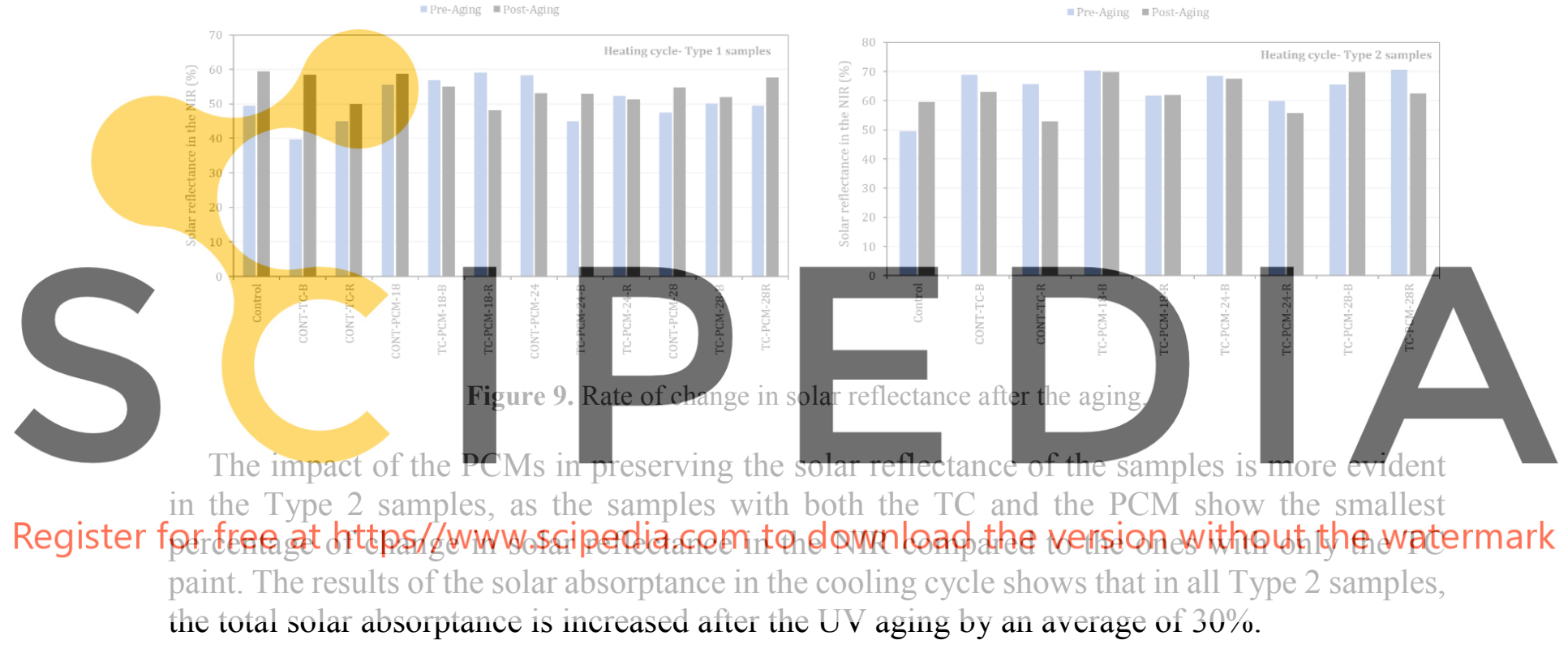

\section{Conclusions}

This study evaluated the effect of accelerated UV aging on the optical performance of cementitious plasters integrated with TC paint and PCMs. This façade finish material intends to regulate thermal stresses exposed to exterior surfaces of building facades due to UV rays and temperature fluctuations. The dynamic properties of the TC paint to control solar radiation and the heat storage capacity of PCMs to control temperature on the surface could help increase the durability of the exterior façade finishing against thermal stresses. The results of the UV aging tests revealed that the impact of aging on the solar reflectance properties of the samples depends primarily on the method of TC paint integration in the cement plaster. Overall, at $45^{\circ} \mathrm{C}$ which is above the transition temperature of the selected TC and the PCMs, the solar reflectance of Type 1 samples with only the TC paint was increased, while the opposite occurs in the Type 2 samples. As the TC color fades on the surface of Type 2 samples, the total range of solar reflectance decreased in samples with only the TC paint. The solar reflectance properties of the 
samples are primarily related to the TC paint. However, a lower rate of change in solar reflectance was observed in the combined PCM and TC scenarios, indicating the benefit of PCMs. A detailed analysis of the performance of the prototypes to regulate thermal stress is underway using temperature cycling tests to observe how the PCMs interact with the TC paints.

\section{Acknowledgements}

The authors wish to thank the Mitacs Organization for the financial support of this research project through the EAccelerate fund. The authors are also grateful to Greg Labbe for his assistance in the experimental tests.

\section{ORCID}

Shahrzad Soudian: https://orcid.org/0000-0001-9838-7327

Umberto Berardi: https://orcid.org/0000-0002-0508-6195

Nadia O. Laschuk: https://orcid.org/0000-0001-6095-3522

\section{References}

Ascione, F., De Masi, R. F., Santamouris, M., Ruggiero, S. and Vanoli, G. P. (2018). Experimental and numerical evaluations on the energy penalty of reflective roofs during the heating season for Mediterranean climate. Energy, 144, 178-199.

Garshasbi, S., and Santamouris, M. (2019). Using advanced thermochromic technologies in the built environment: Recent development and potential to decrease the energy consumption and fight urban overheating. Solar Energy Materials and Solar Cells, 191 (August 2018), 21-32.

Hernández-Pérez, I., Álvarez, G., Xamán, J., Zavala-Guillén, I., Arce, J., and Simá, E. (2014). Thermal performance of reflective materiats applied to exteriar building components - A review. Energy and Building performance of reflective
$80,81-105$.

Jelle, B. P. (2012). Accelera Journal of Materials Scie

Karlessi, T., Santamouris, Development and testing Building and Environument, $46(3)$ dope 576 .
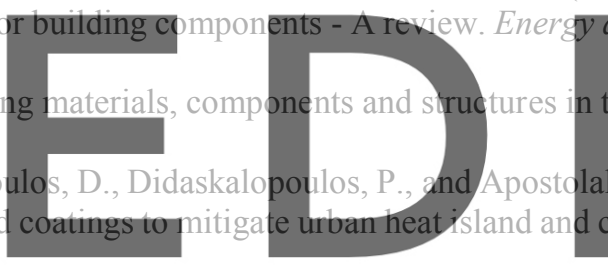
$y$ and Buildings,
in the laboratory.
lakis, K. (2011).
cool bufldings.

Karlessi, T., and Santamouris, M. (2015). Improving the performance of thermochromic coatings with the use of

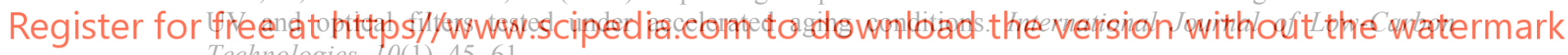
Technologies, 10(1), 45-61.

Natural Resources Canada (NRC) (2016). Solar resource data available for Canada. Retrieved from:

Perez, G., Allegro, V. R., Corroto, M., Pons, A., and Guerrero, A. (2018). Smart reversible thermochromic mortar for improvement of energy efficiency in buildings. Construction and Building Materials, 186, 884-891.

Pisello, A. L., Fortunati, E., Mattioli, S., Cabeza, L. F., Barreneche, C., Kenny, J. M., and Cotana, F. (2016). Innovative cool roofing membrane with integrated phase change materials: Experimental characterization of morphological, thermal and optic-energy behavior. Energy and Buildings, 112, 40-48.

Pisello, A. L. (2017). State of the art on the development of cool coatings for buildings and cities. Solar Energy, $144,660-680$.

Santamouris, M., Ding, L., Fiorito, F., Oldfield, P., Osmond, P., Paolini, R., ... Synnefa, A. (2017). Passive and active cooling for the outdoor built environment - Analysis and assessment of the cooling potential of mitigation technologies using performance data from 220 large scale projects. Solar Energy, 154, 14-33.

Soudian, S. Berardi, U. (2019). Cementitious plasters for façade finishing with phase change materials and thermochromic pigments, IOP Conference Series: Materials Science and Engineering, 609, 062023.

Soudian, S., Berardi, U. Laschuk, N. (2020). Development and thermo-optical characterization of a cementitious plaster with phase change materials and thermochromic paint, Solar Energy, 205,282-291.

Zinzi, M. (2016). Characterisation and assessment of near infrared reflective paintings for building facade applications. Energy and Buildings, 114, 206-213. 